Geografia e Ordenamento do Território, Revista Electrónica

Centro de Estudos de Geografia e Ordenamento do Território

http://cegot.org

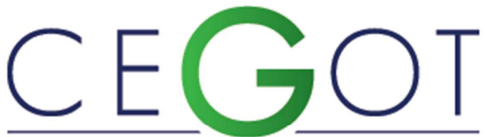

ISSN : 2182-1267

Centro de Estudos de Geografia e Ordenamento do Território

Miramontes Carballada, Á.

Departamento de Xeografía. Universidade de Santiago de Compostela

angel.miramontes@usc.es

\title{
Los paisajes agrarios de España. La evolución de la nueva horticultura y cultivos especializados frente a la agricultura tradicional en la España Atlántica ${ }^{1}$.
}

Referência: Miramontes Carballada, Á. (2014). Los paisajes agrarios de España. La evolución de la nueva horticultura y cultivos especializados frente a la agricultura tradicional en la España Atlántica. Revista de Geografia e Ordenamento do Território (GOT), n.o 5 (junho). Centro de Estudos de Geografia e Ordenamento do Território, p. 161-180

\section{Resumen}

En este trabajo se analiza el paisaje de una de las áreas agrarias españolas donde los cambios y evolución de una agricultura tradicional a una agricultura especializada han sido más significativos. Además se le presta atención a este paisaje agrario atlántico como patrimonio cultural, pues es producto de la explotación económica del potencial ecológico realizado por las distintas sociedades agrarias y grupos humanos que a lo largo de la historia han ocupado, aprovechado y organizado los campos. Este trabajo se apoya en material gráfico y fotográfico para mostrar el patrimonio agrario de la España Atlántica.

\footnotetext{
${ }^{1}$ Para la realización de este trabajo se ha utilizado información del proyecto de investigación titulado: Las unidades básicas de paisaje agrario en España: identificación, delimitación, caracterización y valoración. La España Atlántica y Navarra, financiado por el Ministerio de Ciencia e Innovación del Gobierno Español con la referencia: CSO2009-12225-C05-04.
} 
Palabras clave: paisaje agrario, agricultura tradicional, cultivos especializados, España Atlántica.

\section{Resumo}

Neste trabalho analisa-se a paisagem de uma das áreas agrícolas espanholas onde as mudanças e evolução duma agricultura tradicional para uma agricultura especializada foram mais significativas. Além disso, é dada atenção a esta paisagem agrária Atlântica como património cultural, já que é o produto da exploração económica do potencial ecológico feito pelas várias sociedades agrícolas e dos grupos humanos que ao longo da história têm ocupado, explorado e organizado os campos. Este trabalho é apoiado por material gráfico e fotográfico para mostrar a herança agrícola da Espanha Atlântica.

Palavras-chave: paisagem agrária, agricultura tradicional, cultivos especiais, Espanha Atlântica.

\section{Introducción}

La relación entre agricultura y paisaje es importante y ya ha sido estudiada por un considerable número de autores entre los que destacan (Castelló, A y otros, 2010; Delgado, B. y Ojeda, J. F., 2009; Martínez de Pisón, E., 2003; Mata, R., 1997, 2001, 2002, 2004; Ojeda, J. F., 2004; Silva, R., 2005, 2006, 2008, 2009; Valerià, P., 2007; Zoido, F., 2002). No obstante, los vínculos tradicionales entre agricultura y paisaje están renovándose y reorientándose en las últimas décadas, debido entre otras razones, a normativas como el Convenio Europeo del Paisaje (Consejo de Europa, 2000).

De hecho en el Convenio Europeo del Paisaje, ya en el preámbulo se indica que: "el paisaje es un componente fundamental del patrimonio natural y cultural europeo, [...], un elemento clave del bienestar individual y social y un recurso favorable para la actividad económica y la generación de empleo". Por lo que se comprueba como desde este convenio a los paisajes se les concede la potestad de constituir fundamentos patrimoniales e identitarios, facultades de bienestar social y capacidades de desarrollo (Mata, 2008). Estas nuevas "facetas" del paisaje son las que en gran medida están relanzando la línea de estudio, dentro de la Geografía y otras ciencias, centrada en la reivindicación de los valores patrimoniales de los paisajes agrarios (Silva, 2008). A lo que se une la evolución del concepto patrimonio histórico, inicialmente exclusivo para las obras monumentales y bienes inmateriales localizados principalmente en las áreas 
urbanas (Castillo, 2009). Por lo que siguiendo esta línea de trabajo se analiza un espacio amplio a escala de la península ibérica y con una marcada tradición territorial relacionada con la actividad agrícola como es la España Atlántica.

La España Atlántica comprende una franja en el norte de la Península Ibérica, limitada al sur por las montañas gallegas y la franja centro-meridional de la Cordillera Cantábrica y los Pirineos. Incluye Galicia, Asturias, Cantabria, País Vasco, y un pequeño sector de Navarra, Aragón y Cataluña.

La horticultura atlántica apenas representa un 4,4\% de la total de España, con 8.631 ha, que se localizan fundamentalmente en Galicia. La horticultura ha sido la seña de identidad de muchos paisajes agrarios atlánticos, aunque en cierta decadencia actualmente. De todos modos se pueden establecer dos grupos. El primero, formado por Galicia, donde prácticamente todos sus municipios tienen superficie hortícola y, un segundo, que abarca el resto de la España Atlántica, donde la horticultura y los cultivos especializados se localizan en unos espacios concretos, predominando sus áreas de litoral y prelitoral.

Una de las características que más identifican a este territorio son sus caracteres climáticos. El norte y el oeste de España pertenecen al dominio del clima templado oceánico o atlántico, similar al de muchas regiones de la Europa occidental. Las temperaturas son suaves a lo largo de todo el año, debido fundamentalmente a su proximidad al mar. Tan sólo en el interior montañoso se alcanzan valores fríos más acusados. Por su parte, los inviernos son templados y los veranos frescos y breves. Las temperaturas medias en los meses más fríos están entre los 7 y $10^{\circ} \mathrm{C}$, aunque en las cimas más altas se puede llegar a los $0{ }^{\circ} \mathrm{C}$. En el verano se alcanzan medias de 18 a $20^{\circ} \mathrm{C}$. Estas diferencias producen una amplitud térmica reducida, de apenas $10^{\circ} \mathrm{C}$, que es algo mayor en las montañas.

Las precipitaciones se distribuyen regularmente a lo largo del año, con más de 100 días de lluvia. De modo general, se superan los $800 \mathrm{~mm}$, incluso, los $1.000 \mathrm{~mm}$ anuales. De nuevo la proximidad al mar de las montañas potencia la acción de las borrascas y provoca lluvias orográficas, así como muchos días nubosos, que dejan una insolación de apenas 1.900 horas al año. Las precipitaciones varían mucho entre unas comarcas y otras. Las cuencas del interior de Galicia son las áreas más secas de la España Atlántica, 
mientras que las montañas son las franjas más húmedas, pudiendo superar los 2.000 $\mathrm{mm}$. Por eso, las montañas cantábricas y los Pirineos son las tierras más nivosas de España, pudiendo llegar a los 70 días/año y manteniendo neveros permanentes.

Estas condiciones climáticas, entre otros factores, son las que identifican a la España Atlántica como un medio ecológico en el que predominan los bosques y los prados, lo que convierte a la ganadería en la actividad principal. Domina el poblamiento disperso, como corresponde a una ámbito que tradicionalmente ha tenido un predominio agrícola y ganadero minifundista, en el que las viviendas se encontraban rodeadas por pequeñas explotaciones agrícolas-hortícolas para el autoconsumo, por prados para alimentar al reducido número de reses de cada unidad familiar, destinadas a producir leche para el autoconsumo y carne para alimentarse, mientras los excedentes se comercializaban. Prados que, a su vez, solían estar rodeados por superficies forestales arboladas que han ido cambiando su función, desde la obtención de madera para la construcción de determinadas partes de las viviendas, utensilios de labranza, etc., leña para quemar, y, en ocasiones, para crear rozas con el fin de conseguir superficies adicionales para la agricultura o recolección de alimentos como castañas, setas, etc. En este territorio predomina el régimen de tenencia directa, y la propiedad y la explotación son pequeñas, lo que da lugar a unos niveles bajos de productividad y dificultades en la introducción de innovaciones. A lo que hay que añadir una importante y continua corriente emigratoria hacia los núcleos urbanos e industriales o hacia el exterior, el éxodo rural.

La agricultura se localiza principalmente en las franjas llanas del litoral y, sobre todo, en los valles de los ríos. A pesar de la tradición del policultivo (maíz, patata, frutales, vid), sobre todo en Galicia, en la actualidad se da una clara tendencia hacia el monocultivo especializado en hortalizas (para el autoconsumo y para los mercados urbanos próximos) y en forrajeras (alfalfa, trébol, maíz forrajero) para el autoconsumo. Las comarcas con mayores problemas son aquellas en las que la innovación está tardando más en incorporarse, esto es, el interior de Galicia y las zonas montañosas de la Cordillera Cantábrica, donde a su vez el éxodo rural y despoblamiento demográfico son más fuertes. Por el contrario, el País Vasco (especialmente Álava) y las franjas litorales gallegas están dando muestras de claros avances: especialización en cultivos de calidad, denominaciones de origen... 
La ganadería de bovino, especialmente para leche, es la actividad principal en muchos territorios de la España Atlántica, aunque debido a las consecuencias del éxodo rural, se ha extendido la "ganadería a tiempo parcial". Sin embargo, la integración en la Unión Europea ha planteado dos serios problemas. En primer lugar, la competencia con las producciones bovinas de otros países en los que las explotaciones son mayores, disponen de más pastos, sobre tierras más llanas, y están más modernizadas. En segundo lugar, los ocasionados por la fijación de unos reducidos cupos de producción de leche por una UE hasta ahora excedentaria, que se ve obligada a reducir esta producción, a pesar de que en estos momentos España no llega a cubrir su cupo de producción. El resultado ha sido un claro retroceso del vacuno de leche y la implantación acelerada de innovaciones en las explotaciones que quieren subsistir.

Por último en esta introducción, recordar que la España Atlántica ha contribuido con grandes autores a la historia de la literatura española. Pero lo más interesante es que muchos de estos autores, a lo largo del tiempo y de sus obras, se han centrado frecuentemente en describir las características naturales y sociales de su territorio más próximo. Obras literarias que, en muchas ocasiones, permiten conocer el paisaje agrícola atlántico desde una perspectiva de sentimiento e identidad. De hecho, abundan las obras que permiten apreciar los cambios derivados del abandono de las explotaciones agrarias, el éxodo rural y la lenta tecnificación del campo atlántico. Es evidente que no se limitan a los paisajes hortícolas, sino a los generales, pero merece la pena destacarlos como: José María de Pereda (Santander), Armando Palacio Valdés (Asturias) Emilia Pardo Bazán (A Coruña), Rosalía de Castro (A Coruña) o Miguel de Unamuno (Bilbao), entre otros (http://viajes.michelin.es/Espana-Espana_atlantica; 03-05-2013).

\section{Metodología}

En el proyecto de investigación titulado: Las unidades básicas de paisaje agrario en España: identificación, delimitación, caracterización y valoración. La España Atlántica y Navarra, financiado por el Ministerio de Ciencia e Innovación del Gobierno Español, realizamos una tipificación de los paisajes agrarios apoyada en las ocupaciones del suelo, pues son los aprovechamientos agrarios los que proporcionan las formas, los colores y la 
textura del paisaje. Es evidente que el relieve y el clima constituyen elementos fundamentales en la configuración del paisaje agrario, pero también lo es que ambos quedan incorporado en la clasificación realizada. Por lo que se han separado los paisajes agrarios atlánticos de los mediterráneos y de los canarios, por su disparidad ecológica. Con este análisis se pretende conceptuar, caracterizar y valorar los paisajes agrarios de España como elementos patrimoniales que contribuyan a la revalorización y ordenación territorial.

Además, es evidente que los dominios ecológicos constituyen el escenario de los dominios agrarios, tanto más cuanto la explotación de las ventajas comparativas de cada territorio en el mercado global, exige su especialización en los aprovechamientos para los que tiene mejores condiciones. Eso sí, partiendo de la base de que la agricultura es una actividad basada en la explotación económica del potencial ecológico, la especialización en los esquilmos mejor adaptados al medio ecológico es una garantía de éxito económico y de dinamismo agrario. Por todo ello, la distinción entre la España atlántica y la mediterránea, fue la primera tarea. Ahora bien, esos dominios agrarios admiten numerosos matices, por cuanto la altitud, la exposición y la situación de cada territorio regional y comarcal dan lugar a diferencias, a veces sustanciales.

Para realizar la delimitación de cada uno de los dominios y clases de paisajes agrarios se utilizaron las imágenes de satélite, que permiten cartografiar de una manera bastante ajustada la extensión de cada aprovechamiento. Así como los mapas más recientes disponibles. Concretamente este estudio se apoya fundamentalmente en tres fuentes de valor estadístico y cartográfico: el Corine Land Cover 2006, realizado para toda la Unión Europea, el Censo Agrario de 2009 publicado por el INE a mediados de 2012 y la Encuesta sobre superficies y rendimientos de los cultivos en España (Esyrce) para el 2012 elaborado por el Ministerio de Agricultura, Alimentación y Medio Ambiente.

\section{Resultados}

Los resultados se dividen en 3 pequeños apartados en los que se muestra en primer lugar el cambio de representatividad de la horticultura dentro del paisaje agrario atlántico. En segundo lugar los cambios de una agricultura tradicional hacia una 
agricultura especializada y finalmente la ya consolidación de los cultivos especializados hortícolas dentro del paisaje agrario de la España Atlántica.

\subsection{La horticultura de actor principal a secundario dentro del paisaje agrario Atlántico.}

El mundo agrario en la España Atlántica tiene una clara orientación hacia las actividades tradicionales de leche y carne, que promovieron las políticas estatales en las últimas décadas. Detrás de estas dos actividades se sitúa aún el sector forestal y en cuarto lugar se encuentra la horticultura. Durante las últimas décadas, cabe destacar el gran aumento relativo de la floricultura ornamental y el estancamiento del propiamente hortícola, que se organiza en tres tipos: la huerta familiar, de pequeñas parcelas y destinada al autoconsumo; la explotación al aire libre, en expansión como complemento de la explotación agrícola-ganadera, y la explotación en invernadero, intensiva pero poco abundante en este territorio (Seva, 2002).

La huerta familiar es un modelo de explotación basada en las miniparcelas, y su tendencia es a reducirse paulatinamente, siendo sus productos más representativos la col, repollo, berza, grelo, lechuga, tomate, etc., teniendo una ínfima incidencia en el sector productivo. La horticultura suele concebirse como complemento a la renta principal de la unidad familiar. Sólo las explotaciones con invernadero pueden llegar a adquirir el rango de actividad socioeconómica principal. La estacionalidad de los productos de la huerta se concentra entre junio y septiembre, pudiendo ser algo más temprano en el litoral debido a las circunstancias climáticas.

Otra característica importante es la industrialización, pues dentro de las explotaciones de hortalizas es prácticamente inexistente y su consumo se limita al mercado de fresco. Sólo el cooperativismo ofrece una garantía de calidad en sus productos. Existe una gran diferencia en el modo de trabajo de las explotaciones que pertenecen a cooperativas, pues presentan mayor profesionalización, más superficie, trazabilidad de los productos o tendencia a la producción integrada. El avance del cooperativismo hortícola en el capítulo comercializador a través de los mercados centrales y las grandes superficies es 
muy significativo en las últimas décadas, a la par que la caída de comercialización directa con el comercio particular.

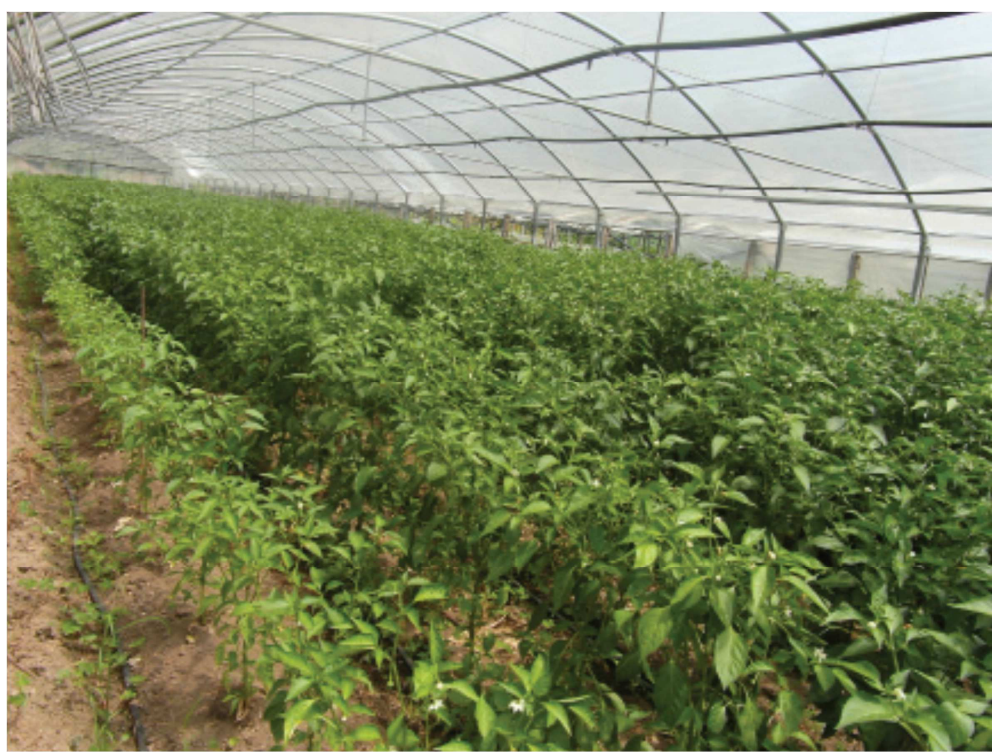

Figura 1. Ejemplo de un invernadero dedicado a la producción de Pimientos de Herbón (conocidos como pimientos de Padrón). Este es uno de los ejemplos donde la actividad hortícola sí adquiere el rango de actividad principal en un territorio de la España Atlántica. Parroquia de Herbón, municipio de Padrón (A Coruna) (Foto: Á. Miramontes, julio de 2013).

De todos modos hay que dejar claro que la horticultura atlántica tiene muy poco que ver con la mediterránea y la del sudeste español. Pero sí constituye una fuente de riqueza y un motor de empleo importante para el mundo rural. No tiene una vocación exportadora, sino que encuentra en el mercado nacional su cuota de mercado, por lo que concentra sus esfuerzos en producir productos de alta calidad y en cantidades reducidas.

Esta evolución de la propia actividad de la horticultura tiene consecuencias en el paisaje agrario, pues no hace muchas décadas todas las casas de aldea tenían en sus proximidades una parcela, de mayor o menor tamaño, dedicada a la producción hortícola. En la actualidad pierden presencia y muchas son ocupadas por otros usos o simplemente abandonadas. Sin embargo, también nos podemos encontrar con parcelas de tamaño medio o grande ocupadas por productos hortícolas que tienen una heterogeneidad de productos mucho menor que en el pasado. Se trata de parcelas dedicadas a uno o dos productos (a diferencia de lo que sucedía en el pasado que había "un poco de todo"), industrializadas y destinadas a la comercialización y no al autoconsumo. 


\begin{tabular}{|l|c|c|}
\hline & España & España Atlántica \\
\hline Secano & 16.302 & 2.756 \\
\hline Regadío & 161.946 & 5.194 \\
\hline Invernadero & 18.832 & 682 \\
\hline Total & 197.081 & 8.631 \\
\hline
\end{tabular}

Figura 2. Superficie ocupada por hortalizas y flores en la España Atlántica según tipo de explotación (hectáreas).

Fuente: elaboración propia a partir de la Encuesta sobre superficies y rendimientos de cultivos de España (ESYRCE, 2012).

De hecho según los datos de la Encuesta sobre superficies y rendimientos de los cultivos en España (Esyrce) para el 2012 elaborado por el Ministerio de Agricultura, Alimentación y Medio Ambiente, nos indica como la España Atlántica (Galicia, Asturias, Cantabria, País Vasco, Navarra y Aragón) tan sólo ocupa el $4,4 \%$ de las hectáreas dedicadas a horticultura y flores de toda España. $Y$ es más, si diferenciamos entre las superficies hortícolas de secano, regadío e invernadero, los porcentajes son de 16,9; 3,2 y 3,6\%, respectivamente. Con lo que se comprueba como la especialización de la España Mediterránea en la producción hortícola cada vez le come más terreno a la España Atlántica. Aunque en la España Atlántica se concentra casi el $20 \%$ de las hortalizas y flores producidas en secano en toda España, en cierta medida se debe al papel de los secanos que esas comunidades tienen en el ámbito mediterráneo, pero el tipo de producción más utilizado en la España Atlántica es el regadío, con más del 60\%.

En cuanto al peso de las Comunidades Autónomas de la España Atlántica en la superficie hortícola, destaca Navarra y le sigue Galicia, si bien Navarra tiene muy poca superficie en el dominio atlántico, destacando ante todo por sus regadíos del Valle del Ebro. Por lo que Galicia se convierte en el territorio que presenta una mayor superficie dedicada a la producción de hortalizas y flores. Concretamente Galicia representa el $67 \%$ de la extensión de hortalizas en secano, el $13 \%$ en regadío y el $47 \%$ en invernadero del total de la España Atlántica. 


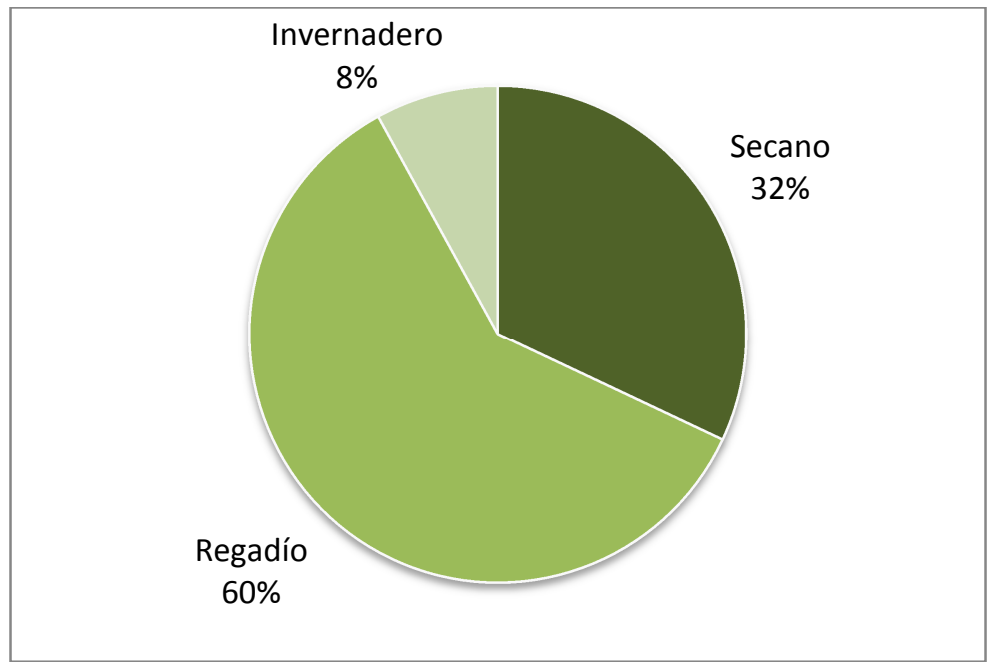

Figura 3. Proporción de superficie de hortalizas y flores por tipo de explotación en la España Atlántica (hectáreas).

Fuente: elaboración propia a partir de la Encuesta sobre superficies y rendimientos de cultivos de España (ESYRCE, 2012).

\begin{tabular}{|l|l|l|l|l|}
\hline & Secano & Regadío & Invernadero & Total \\
\hline Galicia & 1.850 & 665 & 318 & 2.832 \\
\hline Asturias & 121 & 67 & 58 & 246 \\
\hline Cantabria & 29 & 0 & 1 & 30 \\
\hline País Vasco & 156 & 139 & 103 & 398 \\
\hline Navarra & 600 & 4.323 & 202 & 5.125 \\
\hline
\end{tabular}

Figura 4. Superficie ocupada por hortalizas y flores según tipo de explotación (hectáreas).

Fuente: elaboración propia a partir de la Encuesta sobre superficies y rendimientos de cultivos de España (ESYRCE, 2012).

\subsection{Los cambios hacia los paisajes especializados de la agricultura}

\section{tradicional Atlántica.}

La superficie cultivada de la España Atlántica ha estado tradicionalmente dedicada al policultivo para el autoconsumo. Entre otros factores, por el aislamiento e incomunicación en que se encontraban muchas de sus aldeas. Estas superficies cultivadas eran pequeñas parcelas situadas en las proximidades de las viviendas que los productos eran consumidos directamente por la unidad familiar y los cultivos predominantes eran maíz, patatas, frutales, vid, mientras que en las tierras de peor calidad, cebada o centeno. A esta actividad agraria se le unía una ganadería como complemento. Sin embargo, en la actualidad este sistema se va sustituyendo por cultivos de huerta y plantas forrajeras (maíz, alfalfa, prados, etc.) para el ganado. 
Por ello, en este territorio se combinan desde paisajes industrializados, tecnificados, especializados, con otros donde el éxodo rural y el abandono de las explotaciones han provocado que sean espacios poco especializados, con policultivos no adaptados al mercado y con un futuro bastante incierto. Aunque por otro lado, no nos podemos olvidar que se han mantenido a lo largo del tiempo.

Los paisajes de la especialización son consecuencia de la explotación de las ventajas comparativas que cada territorio tiene respecto a los demás. La competencia entre territorios favorece la expansión de unos aprovechamientos y el retroceso de otros. Obviamente, este proceso exige actuaciones técnicas como la concentración parcelaria, la modificación de los asentamientos rurales y las infraestructuras, que, ante la caída de la presión humana debida al éxodo rural, han sufrido un abandono generalizado. De este modo, el campo se queda sin agricultores, de los que solo unos pocos se convierten en empresarios agrarios, que mantienen viva la malla de los paisajes de la especialización, de la competencia y de la globalización, convirtiendo a los aprovechamientos agrarios en la clave del paisaje.
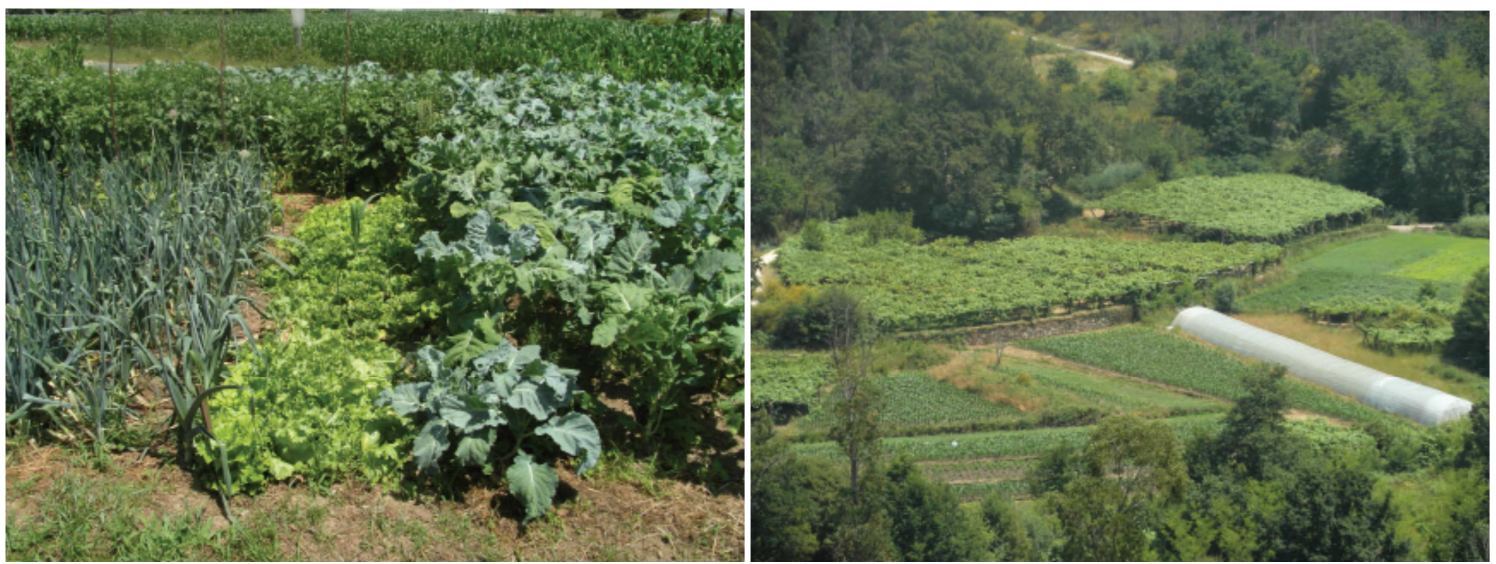

Figura 5. a) En primer plano, cultivos hortícolas destinados al autoconsumo. La diversidad de cultivos es relativamente elevada, aunque en pequeñas cantidades de berzas, lechugas, cebollas, pimientos y, al fondo, maíz para el alimento del ganado. Municipio de A Estrada (Pontevedra). (Foto: Á. Miramontes, julio de 2013). b) Paisaje agrícola atlántico, con cultivos diferentes: invernadero hortícola para comercialización en mercados locales, horticultura al aire libre para el autoconsumo, maíz para la alimentación del ganado, vinas, prados y masas forestales (Foto: Á. Miramontes, julio de 2013).

Otra consecuencia derivada del proceso de especialización es el abandono de los cultivos asociados, que cumplían un papel fundamental como seguro de cosecha en la agricultura tradicional. Aunque el abandono aun ha sido mayor en las áreas marginales, 
debido a las fuertes pendientes, baja calidad de los suelos y características climáticas. A todo ello se suma la poca accesibilidad en algunos sectores de alta montaña, lo que determina un panorama de abandono, del que sólo se libran algunas comarcas montañosas privilegiadas por su valor ecológico y por encontrarse cerca de grandes centros urbanos que las alimentan de turistas (Molinero, 2010).

Por lo que el paisaje agrario atlántico es realmente una creación humana nacida de la ocupación de un territorio que, utilizando las técnicas propias de cada coyuntura y sociedad histórica, se explota, se modela y organiza conforme a los intereses del grupo y de la sociedad en su conjunto, donde estos cambios son los de sustitución de policultivos destinados al autoconsumo por cultivos especializados. De todos modos, se comprueba como la España Atlántica llega a representar el $100 \%$ de la superficie ocupada de un cultivo hortícola en toda España: el grelo. Así como un grupo considerable de cultivos que representan entre el 25 y $30 \%$ del total, como berenjena, acelga, maíz dulce y col repollo.

En cuanto a la localización de los cultivos hortícolas en la España Atlántica, destaca el peso de Galicia frente a los otros territorios, y más teniendo en cuenta que Navarra solo tiene una pequeña porción hortícola en el dominio atlántico. La diversidad de cultivos es variada, pero también se aprecia como hay ciertos cultivos que no se producen en la España Atlántica, como el apio, la sandía o la remolacha. También es destacable comprobar cómo Asturias y Cantabria no encabezan ningún cultivo hortícola en cuanto a superficie utilizada dentro de la España Atlántica (ESYRCE, 2012).

Hay que insistir en que Galicia es, además, el territorio que lidera el número de hectáreas ocupadas por cultivos de hortalizas. También es la Comunidad Autónoma que presenta el mayor porcentaje de huertos vacíos de la España Atlántica, con el 65\%. Por lo que se comprueba que las superficies de horticultura y flores en la España Atlántica siguen teniendo presencia, pero mucho menos que en la España Mediterránea, donde la especialización e intensificación de sus explotaciones hortícolas aumenta con los años, mientras que en aquella retrocede, pues hace décadas "todas" las viviendas de las áreas rurales de Galicia, Asturias, Cantabria o el País Vasco tenían una superficie dedicada a la producción hortícola. 


\begin{tabular}{|c|c|c|c|}
\hline Cultivo o Cubierta & España & España Atlántica & \% España Atlántica \\
\hline Col repollo & 1.469 & 368 & 25 \\
\hline Col brócoli & 2.262 & 13 & 1 \\
\hline Esparrago & 6.517 & 1.008 & 15 \\
\hline Espinaca & 1.041 & 0 & 0 \\
\hline Maiz dulce & 3.152 & 891 & 28 \\
\hline Apio & 128 & 0 & 0 \\
\hline Lechuga & 4.543 & 252 & 6 \\
\hline Lombarda & 161 & 0 & 0 \\
\hline Acelga & 352 & 95 & 27 \\
\hline Escarola & 570 & 0 & 0 \\
\hline Tomate & 9.827 & 769 & 8 \\
\hline Sandia & 9.653 & 0 & 0 \\
\hline Melon & 22.725 & 4 & 0 \\
\hline Calabacin & 2.093 & 92 & 4 \\
\hline Pepino & 1.773 & 12 & 1 \\
\hline Berenjena & 1.034 & 297 & 29 \\
\hline Pimiento & 8.239 & 732 & 9 \\
\hline Puerro & 1.655 & 97 & 6 \\
\hline Alcachofa & 9.063 & 783 & 9 \\
\hline Coliflor & 1.522 & 1 & 0 \\
\hline Ajo & 19.575 & 11 & 0 \\
\hline Cebolla & 17.507 & 854 & 5 \\
\hline Zanahoria & 3.217 & 43 & 1 \\
\hline Judias verdes & 2.616 & 546 & 21 \\
\hline Grelo & 281 & 281 & 100 \\
\hline Guisante verde & 5.625 & 310 & 6 \\
\hline Habas verdes & 915 & 0 & 0 \\
\hline Fresa-freson & 5.896 & 59 & 1 \\
\hline Calabaza & 2.501 & 15 & 1 \\
\hline Remolacha mesa & 430 & 0 & 0 \\
\hline Champiñon & 118 & 0 & 0 \\
\hline Otras hortalizas & 1.271 & 215 & 17 \\
\hline Flores ornamentales & 3.418 & 457 & 13 \\
\hline Huerto vacio & 45.932 & 425 & 1 \\
\hline Hortalizas y flores & 197.081 & 8.631 & 4 \\
\hline
\end{tabular}

Figura 6. Superficie ocupada por hortalizas y flores y porcentaje de la España Atlántica en el total de España (hectáreas).

Fuente: elaboración propia a partir de la Encuesta sobre superficies y rendimientos de cultivos de España (ESYRCE, 2012) 


\subsection{La consolidación de los cultivos especializados en el paisaje agrario Atlántico.}

El abandono de las explotaciones agrarias, el éxodo rural y la lenta tecnificación del campo han sido los hechos más significativos en las últimas décadas dentro del paisaje agrario atlántico. Por otro lado, también aparecen espacios agrarios que se han especializado en un tipo de cultivo concreto y que, en algunos casos, les ha permitido abrirse hueco en los mercados internacionales más competitivos, tales como el del vino, el pimiento o la patata. Pero también se han dado otros aprovechamientos no agrícolas que han generado y están generando una transformación del paisaje y, en ocasiones, beneficios socioeconómicos no pensados en esos territorios, como sucede con los derivados de una ganadería de leche industrializada, o con los aprovechamientos forestales o energéticos.

Un ejemplo claro es el cultivo de la patata. En Galicia se constituyó la Indicación Geográfica Protegida "Patata de Galicia", que tipifica las características del producto (forma, color, tamaño, etc.), establece unas condiciones de envasado y distribución, así como limita los territorios en "zonas" y "subzonas" que pueden acogerse a esta identificación geográfica protegida (www.magrama.gob.es; www.patacadegalicia.es, 0305-2013).

La superficie agrícola dedicada al cultivo se sitúa anualmente en torno a las 1.500 a 1.800 hectáreas. A su vez es importante destacar que "Patata de Galicia" se comercializa en todo tipo de establecimientos, desde las grandes superficies, supermercados a comercios detallistas de alimentación. Los distribuidores y grandes consumidores también pueden encontrar "Patata de Galicia" en los principales mercados centrales, como Mercamadrid, Mercabarna, etc.

En el País Vasco nos encontramos con otro cultivo certificado de patata -Eusko Labelque concede el Gobierno Vasco: la "Patata de Álava". Factores como el clima, el suelo y el hecho de tratarse de un cultivo tradicional han motivado que, hoy en día, la Patata de Álava sea reconocida por los consumidores como un producto de altísima calidad. En cuanto a la evolución en los últimos años de este cultivo, de 1993 a 2011, se comprueba que la producción y el número de productores siguen comportamientos opuestos, pues el número de productores de "Patata de Álava" no superó los 20, desde el 2000 a la 
actualidad, con la salvedad de que en 1995 había más de 120 productores. La producción, por el contrario, pasó de $500.000 \mathrm{~kg}$ (en 2000) a superar los 2.500 .000 kg en 2011. No deja de ser un cultivo con menos presencia en el territorio que el caso gallego, pero sí fácil de identificar y caracterizar en ciertos territorios agrarios (www.euskolabel.net, 03-05-2013).

Otro cultivo de hortalizas que tiene significado en la España Atlántica son las judías cultivadas en Asturias, conocidas como la "Faba Asturiana". Desde 1996, este producto se encuentra catalogado como una I.G.P (Identificación Geográfica Protegida) "Faba Asturiana", que abarca todo el Principado de Asturias. La producción se centra en fincas de labor de unos $6.000 \mathrm{~m}^{2}$ de superficie media, situadas en las riberas de los ríos o terrenos llanos donde es posible la utilización de maquinaria de cultivo. La zona de elaboración y envasado coincide con la de producción. Es importante destacar que las judías secas "Faba Asturiana" o "Fabes de Asturias", forma parte de los cultivos que tradicionalmente se han producido en Asturias. Referencia a este cultivo se encuentra en el estudio de "La Sociedad Económica de Gijón" publicado en el Siglo XIX, en donde se menciona desde distintos aspectos a los cultivos más característicos de esta región, como las "fabes", acompañadas de otros como el maíz, que constituían los principales recursos de las áreas rurales. Se resalta también que en las caserías o explotaciones familiares obtenían los medios económicos con la venta de los productos de mejor calidad, como leche, carne y "fabes" (www.magrama.gob.es; www.faba-asturiana.org; 03-05-2013).

En cuanto a la evolución de la superficie sembrada con fabes desde 1993 a 2012 (las últimas 19 cosechas) la media por cosecha es de 96 hectáreas. De todos modos se aprecia cómo, con pequeños cambios, ha ido aumentando cada año y, desde el 2005 siempre se han superado las 100 hectáreas. La evolución de la producción, en el mismo periodo de tiempo, es más heterogénea. A pesar de las diferencias que se encuentran entre las cosechas, la media es de 142 toneladas/año.

Un cultivo muy similar es el que se realiza en el norte de la provincia de Lugo (Galicia): "Faba de Lourenzá". Se trata de una I.G.P. que abarca el territorio costero de la provincia de Lugo, conocido por A Mariña Lucense. La recolección se realiza desde finales de agosto a finales de noviembre, aunque se pueden encontrar en los mercados durante 
todo el año. Tienen un gran tamaño, entre 19 y $26 \mathrm{~mm}$, y con un peso entre 0,8 g y 1,2 g por unidad. La judía es una planta muy sensible a la falta o el exceso de agua, especialmente en la floración, por lo que requiere suelos con adecuada y regular humedad. La producción se comercializa en envases (sacos) de 0,5 y 1,0 kg de capacidad con destino al consumidor final. Nunca se venden a granel (www.magrama.gob.es; www.fabadelourenza.com; 03-05-2013).

Estas extraordinarias fabas están consideradas entre las de mayor calidad de todas las que se producen en la Península Ibérica. Es por esa razón que, cada vez con más frecuencia, en Asturias para realizar las fabadas, se abastecen de "Faba de Lourenzá", porque absorbe más el sabor y es cremosa y suave.

El pimiento de Herbón, conocido como el Pimiento de Padrón, quizás se puede catalogar como uno de los cultivos hortícolas que más han evolucionado y convertido en un verdadero cultivo especializado. El pimiento de Herbón es un cultivo tradicional que llegó a la parroquia de Herbón, en el municipio gallego de Padrón (A Coruña), en el siglo XVII, de la mano de unos frailes Franciscanos, que trajeron unas semillas del estado mexicano de Tabasco. El cultivo se inició en la huerta del convento y se extendió a toda la parroquia (www.magrama.gob.es;www.pementodelherbon.com; 03-05-2013).

Desde el último tercio del siglo XX, estas explotaciones hortícolas han tenido una serie de cambios e innovaciones que le han permitido ser en la actualidad una DOP (Denominación de Origen Protegida) "Pemento de Herbón".

Dentro de su evolución destaca que los agricultores seleccionan en cada cosecha semillas de las mejores plantas, lo que les asegura un producto óptimo. Otra característica de este producto es que hasta 1970 se cultivaba al aire libre, por lo que el invernadero no fue adquiriendo protagonismo hasta tiempos recientes. La plantación se hace de febrero a marzo en invernadero y de abril a mayo al aire libre. En la actualidad la DOP "Pemento de Herbón" comprende, además del municipio de Padrón, los de Rois, Dodro, Pontecesures y Valga. En todos estos municipios la reducida altitud sobre el nivel del mar, un clima local favorable, un suelo francoarenoso y el saber hacer de los agricultores ocasiona que sea un producto de gran calidad. De hecho se mantiene una "lucha" permanente ante la proliferación de pimientos de características similares, que se producen en otros territorios y se comercializan como Pimientos de Padrón. 
Con una menor presencia dentro del paisaje agrario atlántico que el Pimiento de Herbón, aunque por ello no menos importante, en Galicia existen otras tres I.G.P. de pimiento: I.G.P "Pemento de Arnoia", I.G.P. "Pemento de Oimbra" e I.G.P. "Pemento do Couto". Estas tres I.G.P. tienen una presencia y repercusión socioeconómica menor que el Pimiento de Padrón. Sin embargo, le conceden una personalidad propia a los paisajes agrarios en los que se cultiva (www.magrama.gob.es, 03-05-2013).

Un producto similar al Pimiento de Herbón, es el que se cultiva en tierras del País Vasco bajo la catalogación de Indicación Geográfica Protegida "Gernikako Piperra" o "Pimiento de Gernika". El fruto del "Pimiento de Gernika" se caracteriza por su dulzor, con ausencia de capsicina o bajo contenido, por lo que en las condiciones ambientales del País Vasco no suele presentar picor, es de carne fina y sección longitudinal en forma de triangulo medio (www.magrama.gob.es; www.euskolabel.net; 03-05-2013).

El territorio delimitado de producción coincide con las provincias de Gipuzkoa y Bizkaia y áreas de Álava. Según los datos de la Fundación Kalitatea Fundazioa, la I.G.P. "Gernikako Piperra-Pimiento de Gernika" cuenta con aproximadamente 30 productores y 12 envasadores registrados. El número de productores se ha mantenido en los últimos años, mientras que el de envasadores ha ido creciendo paulatinamente. La producción del pimiento se ha mantenido en una media anual de 600.000 docenas y la superficie cultivada registrada en 15 hectáreas.

Uno de los cultivos más "endémico" y característico de la España Atlántica, y concretamente de Galicia es, el grelo. De hecho según los datos de la Xunta de Galicia se estima que este cultivo representa, aproximadamente, el $20 \%$ de la producción hortícola de Galicia. Cuantificar la producción gallega de grelos es una labor complicada, puesto que, junto con explotaciones destinadas fundamentalmente al abasto de mercados o a la transformación industrial de grelos, conviven muchas otras destinadas al autoconsumo, comercialización no declarada en mercados locales o a la alimentación animal, con aprovechamiento de parte de la producción para consumo humano. En cualquier caso, se estiman unas 8.000 hectáreas dedicadas al cultivo de nabos, con un rendimiento medio de 20 t/ha y una producción total de más de 165.000 t/año y de ellas, unas 30.000 serían para consumo humano. Sin embargo, no fue hasta el 2009, cuando se creó la I.G.P. "Grelos de Galicia”, que abarca a toda la Comunidad Autónoma. 
Aunque dos son las variedades más cultivadas en Galicia, que se identifican con Lugo y Santiago de Compostela, de manera que son conocidas como grelos de una u otra ciudad, sea cual sea el lugar donde se cultiven (www.magrama.gob.es, 03-05-2013).

La provincia de Lugo es la gran productora de grelos de Galicia ("Globo blanco de Lugo"), puesto que este cultivo invernal está presente en todas las comarcas, desde las tierras más bajas hasta las áreas de montaña. El nabo de Lugo también se cultiva con intensidad en la franja norte de la provincia de A Coruña, destacando los grelos del municipio de Monfero. La segunda área con gran producción de grelos es el entorno de Santiago de Compostela ("Grelos de Santiago"), especialmente el sector norte de la comarca, donde gozan de gran fama los grelos del municipio de Ordes, en la que es práctica común la venta de esta verdura a pie de carretera.

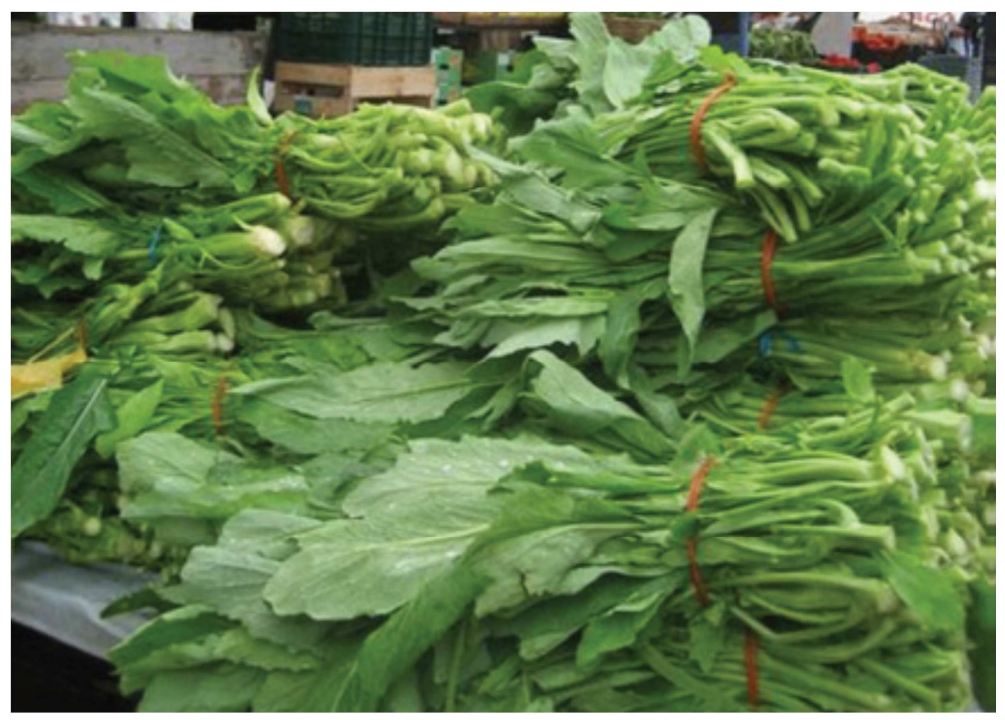

Figura 7. "Atado de grelos". Grelos preparados para su venta en un mercado local (en una "feira galega") (Foto: www.gastronomiaycia.com, 2008).

En cuanto a su comercialización, los grelos en fresco son comercializados en lotes homogéneos en función de la procedencia y la variedad, mediante manojos tradicionales de pesos aproximados de 0,5 o $1 \mathrm{~kg}$, atados por medio de cintas vegetales o de otros materiales autorizados. Los grelos congelados serán clasificados, lavados, escaldados y opcionalmente troceados con carácter previo a la congelación, y envasados en bolsas de materiales y pesos autorizados. Los grelos comercializados en conserva serán elaborados al natural, sin otra adición que el agua de cocción y sal común, sin 
acidificaciones, y presentados en envases metálicos o frascos de vidrio de pesos autorizados. El grelo es una hortaliza que no se puede consumir en crudo.

\section{Discusión y Conclusiones}

La horticultura gallega ha perdido el sentido tradicional que tenía como complemento imprescindible de una agricultura de autoconsumo. En el huerto, favorecido por un clima suave y lluvioso, se tenía de todo: desde la berza, los grelos, patatas, lechugas, cebollas, pimientos, y un sinfín de cultivos de temporada, que iban variando estacionalmente con el devenir del año. Pero este huerto, que aún pervive entre jubilados, agricultores a tiempo parcial, ganaderos, ha dejado de ser un elemento destacable para convertirse en secundario. $Y$, aunque no podemos despreciar su papel en la economía y en el paisaje atlánticos, hoy es marginal.

Frente a esas parcelas hortícolas, dispersas, se han ido consolidando otras de mayor entidad superficial y paisajística: los huertos especializados en cultivos intensivos de hortalizas o flores; en algunos casos, como en Padrón o en La Limia, con carácter general; en otros, como pequeños enclaves que aprovechan vegas o reductos con un especial clima local o buenos suelos, y que han favorecido el mantenimiento de fragmentos hortícolas de poca entidad destinados a los mercados urbanos comarcales y regionales.

Entre ambos modelos, la horticultura atlántica, que cuenta con posibilidades merced a la suavidad del clima y a la abundancia de agua, está siendo desplazada por la horticultura comercial, empresarial y dinámica del mundo mediterráneo, donde sigue una expansión incuestionable, en contraste con la reducción y el poco peso del mundo atlántico.

\section{Referencias}

Bouhier, A. (2001): Galicia: ensaio xeográfi co de análise e interpretación dun vello complexo agrario. Santiago de Compostela, Xunta de Galicia (Original: La Galice: Essai Geographique d'analyse et d'interpretation d'un vieux complexe agrarie, Poitiers, Université de Poitiers, 1979).

Cabo, A. (1989): “Del campo gallego que reseñó Otero Pedrayo al de nuestros días". En actas do Simposio Internacional Otero Pedrayo e a Xeografía de Galicia, Santiago de Compostela, Consello da Cultura Galega: 265-289. 
García Fernández, J. (1974): Los paisajes agrarios de la España Atlántica. Departamento de Geografía, Universidad de Valladolid, $432 \mathrm{p}$.

López Iglesias, E. (2000) “A dinámica recente e futura da poboación ocupada no sector agrario". En Fernández Leiceaga, X. (dir.): Avellentamento demográfico e consecuencias socioeconómicas, Vigo, Edicións Xerais: 141-179.

MAGRAMA(2013): Encuesta sobre superficies y rendimientos de cultivo. ESYRCE. Resultados 2012. Secretaría General Técnica Subdirección General de Estadística. Madrid, 166 p.

Miramontes, Á. (2007): A Xeografía Física de Galicia. Edicións Lóstrego. Santiago de Compostela, 94 p.

Miramontes, Á. y Alonso, Mạ. P. (2001): “Adaptación de un paisaje agrícola tradicional a nuevos usos que lleven a la sostenibilidad. El ejemplo del municipio de A Estrada (Pontevedra)". En actas del IV Coloquio Hispano-Portugués de Estudios Rurales. IDEGA-USC. Santiago de Compostela (formato CD).

Molinero Hernando, F (2010): “Paisajes y economías agrarias: del policultivo de subsistencia a la especialización agraria mundial)". Ponencias del XV Coloquio de Geografía Rural: Geografía y Desarrollo Rural. Territorio, Paisaje y Patrimonio. Madrid, Ministerio de Medio Ambiente y Medio Rural y Marino: 556.

O’Flanagan, P. (1996): Xeografía Histórica de Galicia, Edicións Xerais, Vigo.

Pérez Alberti, A. (1999): “Dinámica ecogeográfica y construcción del espacio en Galicia”. En colecció homenatges. Profesor Joan Vilá Valentí. El seu mestratge en la Geografía Universitaria, Barcelona, Universitat de Barcelona: 1175-1185.

Seva Rivadulla, F. A. (2002): “La horticultura en Galicia”. En revista electrónica Revista Horticultura, número 160 pp. 1-4.

Torres Luna, Ma. P. (2000): “Les paysages agraries de la Galicie dans le contexte de I'Arc Atlantique Européen”, en SOUMAGNE, J. (coord.), Les nouveaux espaces ruraux de L'Europe Atlantique, Poitiers, Maison des Sciences de L'Homme et de la Societé, Université de Poitiers, ITEEM ICOTEM, pp. 255-265. 